\title{
The efficacy of a chitin synthesis inhibitor against field populations of organophosphate-resistant Aedes aegypti in Brazil
}

\author{
Nathalia Giglio Fontoura ${ }^{1,2}$, Diogo Fernandes Bellinato ${ }^{1,2}$, \\ Denise Valle ${ }^{1,2}$, José Bento Pereira Lima ${ }^{1,2 /+}$ \\ ${ }^{1}$ Laboratório de Fisiologia e Controle de Artrópodes Vetores, Instituto Oswaldo Cruz-Fiocruz, Rio de Janeiro, RJ, Brasil \\ ${ }^{2}$ Laboratório de Entomologia, Instituto de Biologia do Exército, Rio de Janeiro, RJ, Brasil
}

The mosquito Aedes aegypti is the main focus of dengue control campaigns. Because of widespread resistance against conventional chemical insecticides, chitin synthesis inhibitors (CSIs) are considered control alternatives. We evaluated the resistance status of four Brazilian Ae. aegypti populations to both the organophosphate temephos and the pyrethroid deltamethrin, which are used in Brazil to control larvae and adults, respectively. All vector populations exhibited high levels of temephos resistance and varying rates of alterations in their susceptibility to pyrethroids. The effect of the CSI novaluron on these populations was also investigated. Novaluron was effective against all populations under laboratory conditions. Field-simulated assays with partial water replacement were conducted to evaluate novaluron persistence. Bioassays were continued until an adult emergence inhibition of at least $70 \%$ was attained. We found a residual effect of eight weeks under indoor conditions and novaluron persisted for five-six weeks in assays conducted in an external area. Our data show that novaluron is effective against the Ae. aegypti populations tested, regardless of their resistance to conventional chemical insecticides.

Key words: Aedes aegypti - chitin synthesis inhibitors - temephos - deltamethrin - novaluron - cross-resistance

Among the arboviruses transmitted by mosquitoes throughout the world, dengue is presently the most relevant; it is endemic to all of the continents, except Europe (Nogueira et al. 2001, Forattini 2002, Claro et al. 2004). Brazil has an alarming dengue incidence with several outbreaks all over the country and an increasing incidence of severe cases. Therefore, major public health campaigns target this disease (Teixeira et al. 1999, Câmara et al. 2007, MS/SVS 2009).

Specific drugs and an effective vaccine against dengue virus are not yet available (Durbin \& Whitehead 2010). Consequently, the only way to control the dengue epidemiological network is to target the virus' vector, Aedes aegypti (Medronho 2006, Braga \& Valle 2007). Although the elimination of potential Aedes breeding sites is increasingly considered a crucial component of dengue control, the utilisation of chemical insecticides is still a common measure. Until very recently, the most commonly used insecticides against Aedes in Brazil were the organophosphate temephos and the pyrethroid deltamethrin, which are used to control the larval and adult populations, respectively (Braga \& Valle 2007).

The continuous use of chemical insecticides can lead to the dissemination of resistance and the consequent failure of the control efforts. Therefore, alternative methods of controlling disease-transmitting vectors are urgently needed. Two examples are entomopathogenic bacteria and insect growth regulators (IGRs).

Financial support: CNPq, FIOCRUZ, SVS-MS, FAPERJ

+ Corresponding author: jbento@ioc.fiocruz.br

Received 9 June 2011

Accepted 29 November 2011
The biological insecticide Bacillus thuringiensis serovar israelensis (Bti) has been employed against $A e$. aegypti in various municipalities of Brazil. However, the reduced field persistence of commercially available $B t i$ formulations is an obstacle; under tropical conditions, the maximal residual effect observed lasted four weeks (Lima et al. 2005).

In contrast to the classical chemical insecticides and biolarvicides, IGRs are not directly toxic, but act selectively on the development, metamorphosis or reproduction of the target insect species (Hoffmann \& Lorenz 1998, Martins \& Silva 2004). Among IGRs, the chitin synthesis inhibitors (CSIs) act by interfering with the synthesis or deposition of chitin on the exoskeleton or other chitinised internal structures, such as the peritrophic matrix (Merzendorf \& Zimoch 2003, Merzendorf 2005).

Novaluron is a CSI that is already utilised in agriculture. It is highly effective against Coleoptera, Homoptera and Lepidoptera larvae of several crop pests (Mulla et al. 2003). It can act through ingestion, as verified in the larvae of the moth species Spodoptera littoralis and Helicoverpa armigera, or through contact, as reported with the flies Bemisia tabaci and Trialeurodes vaporariorum (Ishaaya et al. 1996, 1998). Novaluron is also efficient against Ae. aegypti larvae, as reported by Mulla et al. (2003) and Arredondo-Jiménez and Valdez-Delgado (2006). Because novaluron is recommended by the World Health Organization for use in drinking water, it represents a potential tool in the control of the dengue vector (WHO 2007).

We quantified the effect of novaluron against Rockefeller, a reference Ae. aegypti strain susceptible to insecticides. These data enabled later comparisons with results obtained in the laboratory with wild Ae. aegypti populations that exhibit varying resistance levels to temephos and deltamethrin, the two most frequently 
used chemical insecticides in Brazil. The persistence of novaluron under field-simulated conditions was also evaluated to assess its potential contribution to resistance management strategies for controlling the dengue vector in Brazil.

\section{MATERIALS AND METHODS}

Mosquitoes - Four populations of mosquitoes from three regions of Brazil were evaluated: Henrique Jorge, a district of Fortaleza, at the state of Ceará, Aracaju, at the state of Sergipe, Cuiabá, at the state of Mato Grosso, in the Central West, and Uberaba, state of Minas Gerais, in the Southeast (Fig. 1). With the exception of Fortaleza, the samples were obtained between August-December of 2005 by collecting eggs with ovitraps installed to cover the whole municipalities, according to Braga et al. (2000) and Lima et al. (2003). Fortaleza eggs were collected with ovitraps in the district of Henrique Jorge, a location chosen because of its high infestation rates. In this case, 40 ovitraps were installed between MarchOctober of 2006 (Paixão 2007).

Generations F1 through F4 were used for the bioassays listed in Table I. The Rockefeller strain, an insecticide-susceptible reference strain, was used as a control for each test (Hartberg \& Craig-Jr 1970). Mosquito rearing and experimentation were performed at $26 \pm 1^{\circ} \mathrm{C}$ and relative humidity $70 \pm 10 \%$.

Insecticides - The CSI novaluron (Rimon $100 \mathrm{EC}$ ) and technical grade temephos (Fersol 90\%) were generously provided by Agricur and the Brazilian Health Ministry, respectively. Technical grade deltamethrin (99.1\%) was purchased from Bayer.

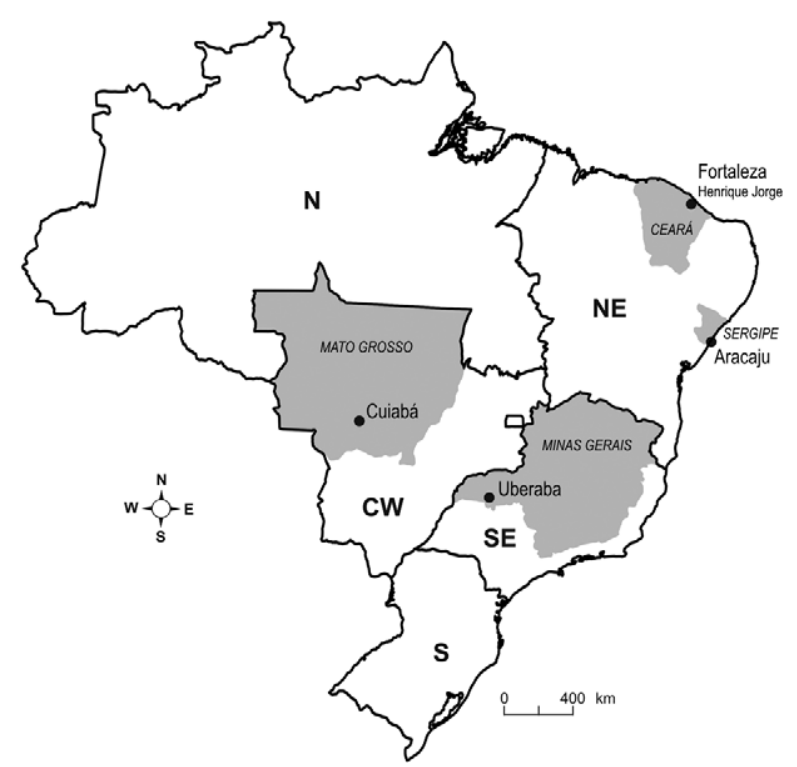

Fig. 1: Brazilian map showing the states (grey) and municipalities used in the study. The continuous lines indicate the different Regions of the country: N: North; NE: Northeast; SE: Southeast; S: South; CW: Central-West.
Laboratory bioassays - Temephos quantitative bioassays were performed according to Braga et al. (2004), following procedures recommended by WHO (1981). A complete test consisted of at least 10 insecticide doses, with four replicates per dose and 20 larvae per replicate. Four tests were performed on each population on different days. Mortality rates were recorded $24 \mathrm{~h}$ after exposure to the insecticide. Lethal concentrations (LCs) and resistance ratios (RRs) were calculated by probit analysis (Raymond 1985) and by comparison with Rockefeller $\mathrm{LC}$ values, respectively. According to criteria adopted in Brazil in 2006, a temephos RR above 3.0 represents the cut-off level for triggering resistance management strategies (Montella et al. 2007).

Novaluron emergence inhibition (EI) quantitative assays were adapted from Martins et al. (2008). Briefly, L3 larvae were exposed to eight concentrations of novaluron in transparent plastic cups containing $150 \mathrm{~mL}$ of solution. Ten larvae per replicate and eight replicates per concentration were used. Four control replicates consisted of larvae exposed to the higher acetone volume used in the experimental conditions $(120 \mu \mathrm{L})$. A small amount of cat food (Friskies ${ }^{\circledR}$, Purina, Camaquã/RS, Brazil) was added on the first day. The plastic cups were covered with a nylon mesh in order to avoid adult escape. Larvae were kept in contact with the CSI until death or adult emergence. Mortality at each stage was assessed daily and the success of adult emergence was confirmed by counting the number of pupae exuvia (Mulla 1974, Mulla et al. 2003). At least three assays were performed for each population, each on different days.

Qualitative assays with adults were performed using deltamethrin-impregnated bottles, essentially as described by da-Cunha et al. (2005), that was adapted from Brogdon and McAllister (1998). Each assay consisted of three bottles impregnated with the insecticide $(5 \mu \mathrm{g} /$ bottle) and one control bottle impregnated only with acetone that was used as the solvent. Each bottle received 20 non-blood fed adult females that were one-three days old. Knockdown was registered at 15 min intervals for up to $2 \mathrm{~h}$. Mosquitoes were then transferred to recovery cages free of insecticide and mortality was registered again $24 \mathrm{~h}$ later. Each population was submitted to four complete assays on different days. Interpretation of these qualitative assays was performed according to the Davidson and Zahar (1973) criteria modified by WHO (1998) and already employed for use with the bottle assays by da-Cunha et al. (2005), in which mortality rates above $98 \%$ and below $80 \%$ indicate susceptibility and resistance, respectively. Intermediate values suggest an alteration of the susceptible status of the population.

Field-simulated assays - Field tests were conducted in two areas, one indoors and one at a partially shaded external location (Lima et al. 2005), both in 70 L plastic buckets. These receptacles are frequently used for domestic water storage. L3 larvae from the Henrique Jorge and Aracaju populations were tested. Rockefeller larvae were exposed in parallel as a susceptible control. The assays were assembled and monitored according to previously defined parameters (MS/SVS 2006). A total of 
TABLE I

Effect of the organophosphate temephos on larvae from Brazilian Aedes aegypti populations

\begin{tabular}{lcccccc}
\hline Population & Generation & Slope & $\mathrm{LC}_{50}$ & $\mathrm{RR}_{50}$ & $\mathrm{LC}_{90}$ & $\mathrm{RR}_{90}$ \\
\hline Rockeffeler & - & $5.8 \pm 0.2$ & 0.00217 & 1.0 & 0.00361 & 1.0 \\
Cuiabá (MT) & $\mathrm{F} 4$ & $4.7 \pm 0.2$ & 0.01199 & 5.5 & 0.02267 & 6.3 \\
Uberaba (MG) & $\mathrm{F} 4$ & $4.2 \pm 0.2$ & 0.01961 & 9.0 & 0.03990 & 11.1 \\
Aracajú (SE) & $\mathrm{F} 1$ & $3.5 \pm 0.2$ & 0.01985 & 9.2 & 0.04625 & 12.9 \\
Henrique Jorge (CE) & $\mathrm{F} 3$ & $4.6 \pm 0.2$ & 0.08041 & 37.1 & 0.15015 & 41.6 \\
\hline
\end{tabular}

lethal concentrations (LC) are presented in $\mathrm{mg} / \mathrm{L}$ and resistance ratios (RR) were calculated using Rockefeller as reference. CE: state of Ceará; MG: state of Minas Gerais; MT: state of Mato Grosso; SE: state of Sergipe.

three simulated field tests were performed: two in the external area (from March-May and from October-December 2007) and one indoors.

In each area and for each population, including the Rockefeller strain, two conditions, with or without water replacement, were evaluated in triplicate, totalling 18 buckets with novaluron per field test. Three additional buckets of water received Rockefeller larvae and were used as an internal control for the assays. Each experimental bucket consisted of $50 \mathrm{~L}$ of a $20 \mu \mathrm{g} / \mathrm{L}$ novaluron solution in tap water, the recommended concentration employed by the Brazilian Health Ministry in field assays (Mulla et al. 2003). Novaluron was applied only once. In each area, the recipients were randomly placed (Montella et al. 2007) and covered with a nylon mesh. Each week, $50 \mathrm{~L} 3$ larvae and $1 \mathrm{~g}$ of cat food were directly added to each bucket. Mortality at each stage was scored every two days and emerging adults were removed. The success of adult emergence was confirmed by counting the number of pupae exuvia, as stated above for the laboratory bioassays. Before adding a new group of larvae, the remaining specimens from the previous week were transferred to a floating plastic apparatus kept inside the buckets. These devices were covered with two strips of nylon mesh to ensure permanent contact with the CSI and to avoid adult escape (Supplementary data). This procedure enabled us to separate larvae from different experimental points. Monitoring of the different batches of larvae proceeded until death or adult emergence of all specimens. In the water replacement condition, $10 \mathrm{~L}$ of the solution was removed three times a week and replaced with an equivalent amount of tap water in order to simulate domestic water usage.

Water temperature and $\mathrm{pH}$ were recorded weekly. The assays progressed until the residual effect, defined as the time necessary to inhibit more than $70 \%$ of the adult emergence, was attained.

Statistical analysis - Comparisons between mortality results obtained with the chemical insecticides (temephos and deltamethrin) and novaluron were performed using the Spearman correlation. Differences among populations in the simulated field tests, as well as comparisons between conditions with and without water replacement were assessed using Mann-Whitney analysis.

\section{RESULTS}

Laboratory bioassays - All field populations exhibited high levels of resistance to temephos (Table I). The Ae. aegypti population from Henrique Jorge revealed an extremely high temephos resistance ratio $\left(\mathrm{RR}_{90}=41.6\right)$. Despite this high RR, all populations had slope values lower than the Rockefeller strain, indicating that they had not yet attained a homogenous temephos resistance status.

Table II shows the mortality levels after exposure to a diagnostic dose of the pyrethroid deltamethrin. According to WHO criteria (see Materials and Methods), no evaluated field population can be considered truly susceptible. When mortality after $30^{\prime}$ exposure is taken into account, two of the populations were deltamethrin resistant and the other two presented alterations in their susceptible status. After a 24-h period of recovery in the absence of the insecticide, the Uberaba and Henrique Jorge populations still exhibited an altered susceptibility status.

We evaluated the susceptible Rockefeller strain before testing field populations to have a comparison parameter. We confirmed the dose-dependent effects induced

TABLE II

Effect of exposure of Aedes aegypti Brazilian adults to a deltamethrin diagnostic dose

\begin{tabular}{lcc}
\hline Population & $\begin{array}{c}30 \text { ' exposure } \\
(\%)\end{array}$ & $\begin{array}{c}24 \text { h recovery } \\
(\%)\end{array}$ \\
\hline Rockefeller & $\mathrm{S}(100)$ & $\mathrm{S}(100)$ \\
Cuiabá (MT) & $\mathrm{I}(86)$ & $\mathrm{S}(98.4)$ \\
Uberaba (MG) & $\mathrm{R}(78.7)$ & $\mathrm{I}(82.5)$ \\
Aracajú (SE) & $\mathrm{I}(91.6)$ & $\mathrm{S}(98.9)$ \\
Henrique Jorge (CE) & $\mathrm{R}(77.7)$ & $\mathrm{I}(92.6)$
\end{tabular}

mortality rate after 30' exposure on impregnated bottles and $24 \mathrm{~h}$ recovery are shown. Status of resistance, according to Davidson and Zahar (1973) modified by WHO (1998) (I: incipient resistance; R: resistance; S: susceptibility). For each population, 240 adult females were tested (see Materials and Methods). CE: state of Ceará; MG: state of Minas Gerais; MT: state of Mato Grosso; SE: state of Sergipe. 
by novaluron, similar to other IGR compounds (Martins et al. 2008). Susceptibility to novaluron was observed in all populations (Table III). One population, Aracaju, was even slightly more susceptible to novaluron than the Rockefeller reference strain (RR values below 1.0), despite its high temephos resistance status (Table I) and its alteration in susceptibility to deltamethrin (Table II). Henrique Jorge mosquitoes, the most temephos-resistant Brazilian population detected to date by our group, also presented the highest novaluron RR. However, this value remained below 2.0, indicating that the Henrique Jorge mosquitoes remained susceptible to novaluron. Interestingly, this population also presented the lowest slope value, indicative of a higher heterogeneity, compared with the other evaluated populations. Fig. 2 shows a comparison of the linear regression curves obtained with these populations after exposure to temephos or novaluron. The susceptibility to novaluron of all populations, regardless of their temephos resistance status, is evident.

When mortality was evaluated at each stage (Fig. 3), we confirmed the dose-dependent effect of novaluron on Aedes development. Although mortality was detected in larvae, pupae and adults, the higher the dose, more premature it is. By contrast, adults were obtained only after exposure to the lower concentrations of novaluron. Evaluation of the mortality at each stage (Fig. 3) confirmed the data on the inhibition of emergence (Table III). The Henrique Jorge mosquitoes, the population with the highest novaluron RR, were the only population in which adults were obtained after exposure to the highest concentration tested. In contrast, the Aracaju mosquitoes, which seem slightly more sensitive than the Rockefeller strain (RR below 1.0), were prevented from maturing to adults by $0.3 \mu \mathrm{g} / \mathrm{L}$ novaluron, while the Rockefeller mosquitoes were prevented from maturing to adults at a higher concentration $(0.4 \mu \mathrm{g} / \mathrm{L})$. Cuiabá and Uberaba mosquitoes exhibited similar RR values and also comparable profiles of mortality per stage. Fig. 4 illustrates the morphological aspects of Ae. aegypti specimens at all stages after exposure to novaluron.

Field-simulated assays - Fig. 5 shows the results of three field-simulated experiments with novaluron; two experiments were conducted in a partially shaded external area and one was conducted indoors. Novaluron was added only at the beginning of the experiment. As stated above, each of the three field-simulated experiments was performed with and without water replacement ( $20 \%$ of the container's volume 3 times a week). The two field populations chosen were the Henrique Jorge and Aracaju mosquitoes, which had previously exhibited the highest and lowest novaluron RR values, respectively (Table III).

In many cases, temperature can contribute to or even be the main reason for developmental constraints or high mortality rates. We made weekly measurements of environmental and water temperatures (Fig. 5, lower pan-
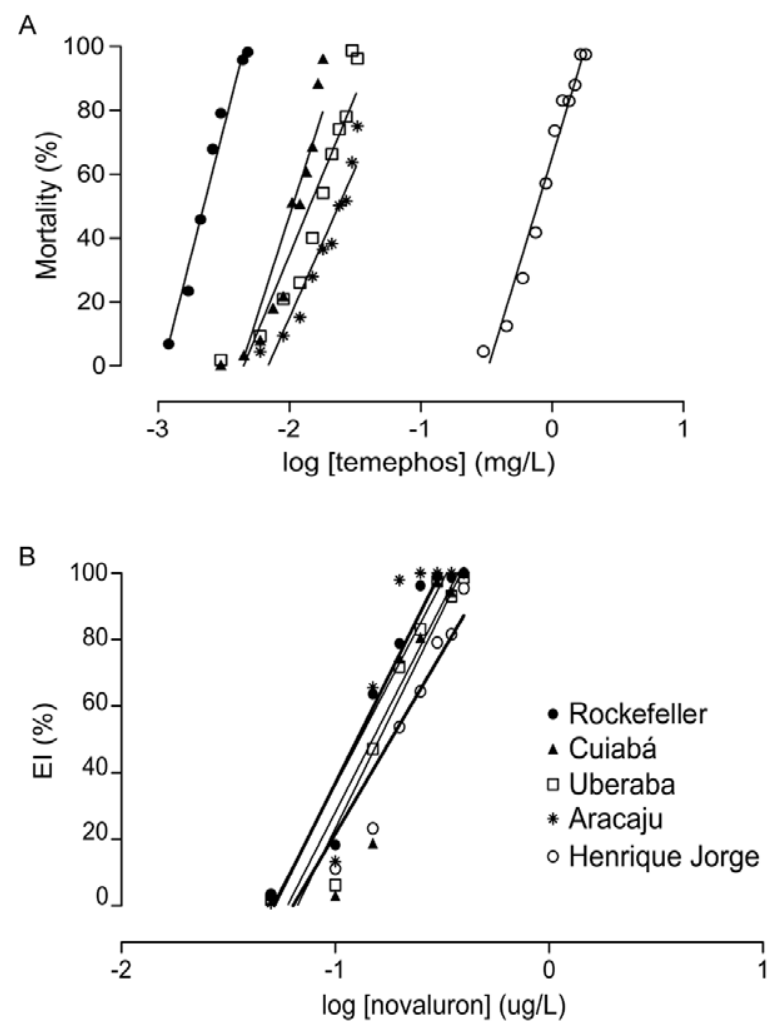

Fig. 2: linear regression curves of Aedes aegypti (A) mortality after a $24 \mathrm{~h}$ exposure to temephos or (B) adult emergence inhibition (EI) after contact with novaluron.

TABLE III

Effect of novaluron on larvae from Brazilian Aedes aegypti populations

\begin{tabular}{lccccc}
\hline Population & Slope & $\mathrm{EI}_{50}$ & $\mathrm{RR}_{50}$ & $\mathrm{EI}_{90}$ & $\mathrm{RR}_{90}$ \\
\hline Rockefeller & $6.3 \pm 0.3$ & 0.135 & 1.00 & 0.216 & 1.00 \\
Cuiabá (MT) & $8.6 \pm 1.8$ & 0.183 & 1.35 & 0.258 & 1.20 \\
Uberaba (MG) & $6.3 \pm 0.6$ & 0.163 & 1.21 & 0.261 & 1.21 \\
Aracajú (SE) & $9.8 \pm 1.3$ & 0.132 & 0.98 & 0.179 & 0.83 \\
Henrique Jorge (CE) & $4.7 \pm 0.3$ & 0.197 & 1.46 & 0.369 & 1.71 \\
\hline
\end{tabular}

adult emergence inhibition concentrations (EI) are presented in $\mu \mathrm{g} / \mathrm{L}$ and resistance ratios $(\mathrm{RR})$ were calculated using Rockefeller as susceptible reference. CE: state of Ceará; MG: state of Minas Gerais; MT: state of Mato Grosso; SE: state of Sergipe. 

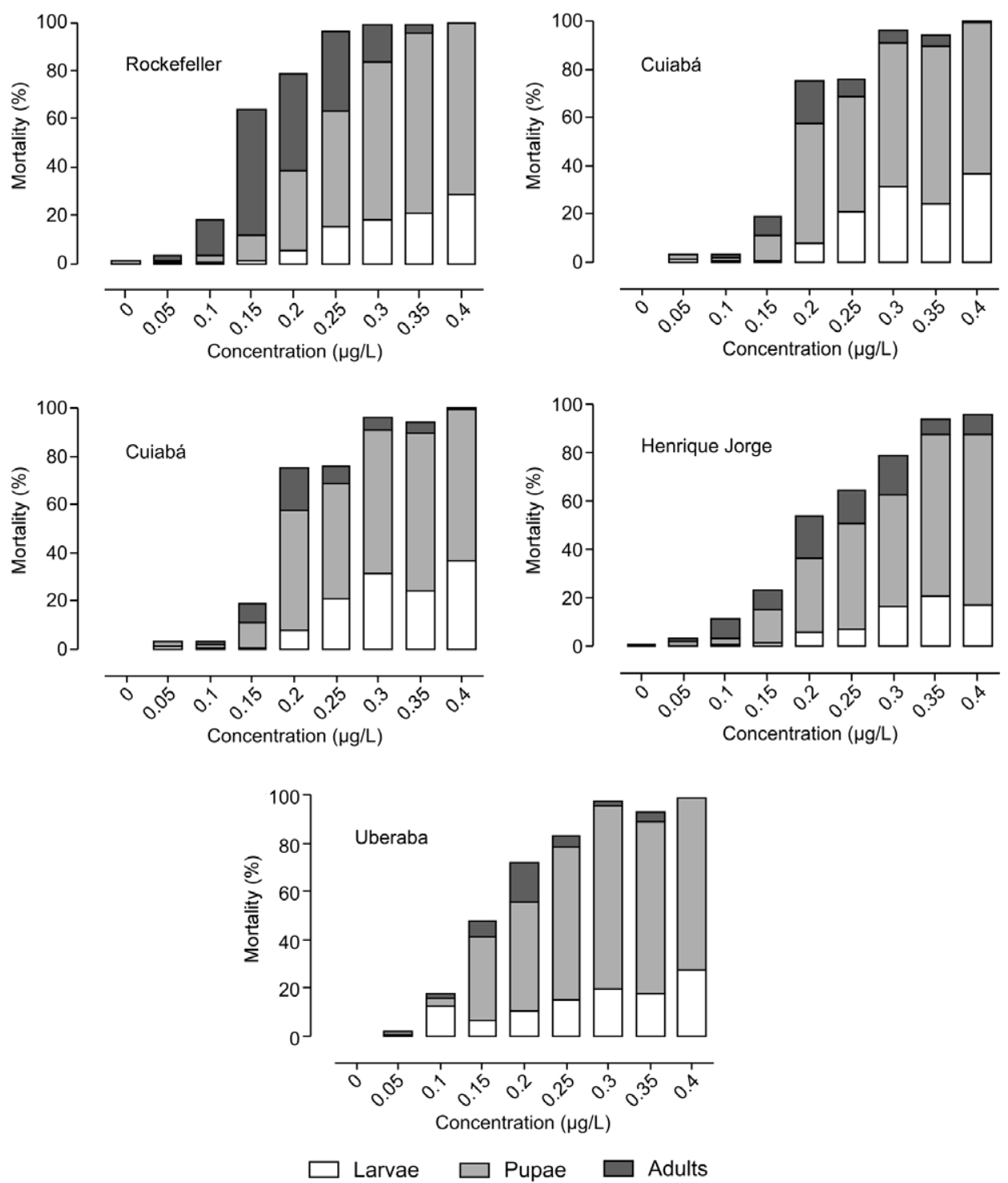

Fig. 3: stage-specific induced mortality of Aedes aegypti exposed to different novaluron concentrations at the L3 larva instar.

els). The temperatures in the indoor assay were lower and less variable than the external tests. Additionally, the environmental temperature of the external area was, in general, more variable than the water temperature.

The upper panels of Fig. 5 show the results of the water replacement condition of the three simulated assays (see Materials and Methods for details). A comparison of these results with the results of the condition without water replacement did not reveal any significant difference in adult EI ( $p>0.05$; data omitted to improve clarity). Novaluron completely inhibited adult emergence of all of the populations after four weeks in the first (March-May) external field-simulated assay and after three weeks in the second (October-December). It also induced more than $70 \%$ mortality after six weeks in the first and after five weeks in the second assay. Control mortality remained below $10 \%$ in all cases during these assays with the exception of the 4th week of the second assay, when mortality reached $16 \%$. In the indoor simulated field assay, which provided a more constant environment, novaluron was effective for at least eight weeks for both populations; the same result was observed against the Rockefeller strain used as a susceptible control. No significant differences in novaluron persistence under field simulated conditions were found between the Henrique Jorge and Aracaju populations or between them and the Rockefeller mosquitoes $(p>0.05)$. Additionally, in all cases larval mortality was significantly higher after the 5 th day of contact with novaluron (data not shown).

\section{DISCUSSION}

The chemical control of insect pests and parasite vectors is still largely employed all around the world. In Brazil, the organophosphate temephos has been used for decades to control the larvae of the dengue vector $A e$. aegypti and reports of temephos resistance date from 


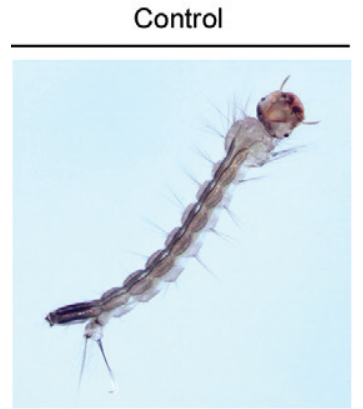

larva

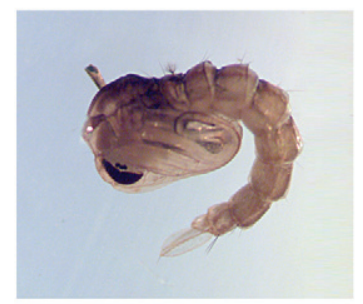

pupa

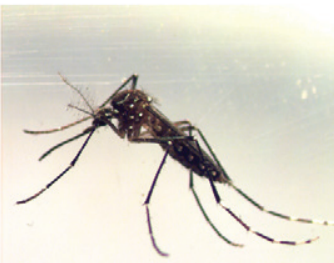

adult
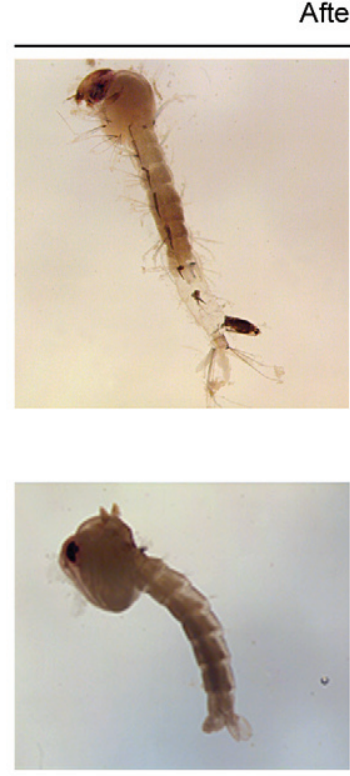

white

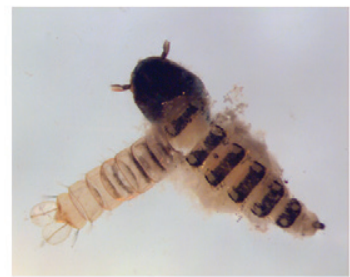

partially emerged

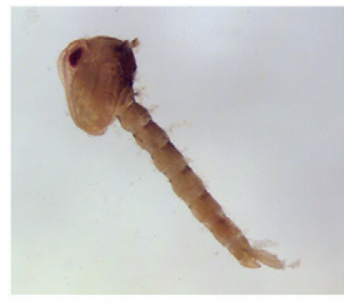

distended



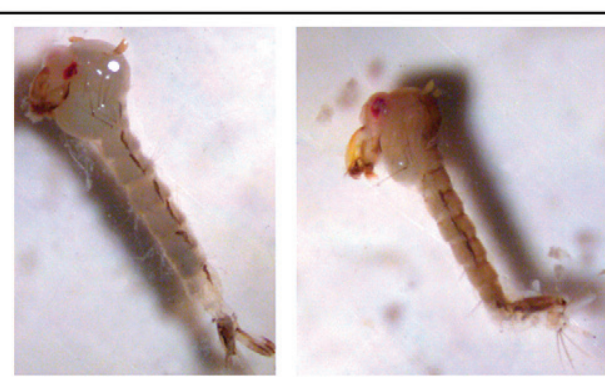

pre-pupa


tarsi deformed

Fig. 4: morphological aspect of Aedes aegypti specimens after exposure to novaluron. The left panel shows control larvae, pupa and adults, while at the right side the chitin synthesis inhibitor exposed larva, pupa or mosquitoes are shown. Identification of anomalies based on Talaat and Mulla (1984) and Braga et al. (2005).

1998 (Macoris et al. 1999, Lima et al. 2003). The RR values obtained in this work indicated temephos resistance in all of the populations evaluated. Temephos resistance was even found in Cuiabá in contrast to an earlier report from that locality (Campos \& Andrade 2003), suggesting recent local resistance dissemination (MS/SVS 2007). High temephos RR values were found at localities from Northeast and Southeast Brazil, corroborating previous data (Lima et al. 2003, Braga et al. 2004, Macoris et al. 2007, Montella et al. 2007). Strikingly, the Henrique Jorge population exhibited very high RR levels, although these assays were performed with specimens reared in the laboratory for three generations without insecticides. However, it should be noted that egg collection was not representative of the whole municipality of Fortaleza; ovitraps were installed in one specific district previously known for its high infestation levels and, consequently, intensive insecticide selection pressure. Finally, it is important to mention that the temephos resistance status of the field populations examined was more heterogeneous than the Rockefeller reference strain, as judged by the slope values obtained.
Pyrethroids were introduced for the control of $A e$. aegypti adults on a national scale in Brazil in 2001. However, resistance to pyrethroids was detected soon after the introduction of this class of pesticides (daCunha et al. 2005). Diagnostic tests with the pyrethroid deltamethrin revealed an altered susceptibility status, or even resistance, for all of the evaluated populations. It is interesting to note that the Henrique Jorge mosquitoes, the population found to have the highest temephos resistance ratio, exhibited pyrethroid incipient resistance after $24 \mathrm{~h}$ of recovery.

Novaluron is considered a potential novel larvicide against Ae. aegypti because WHO has approved its usage in drinking water (WHO 2007). However, care should be taken to avoid potential cross-resistance with other insecticides already employed for dengue vector control.

The concentration of novaluron is directly proportional to both Ae. aegypti mortality rates and to the precotity of mortality, as previously verified by Mulla et al. (2003). These characteristics are shared by the CSI triflumuron for Ae. aegypti, as shown by Martins et al. (2008). Ae. aegypti is apparently more susceptible to 

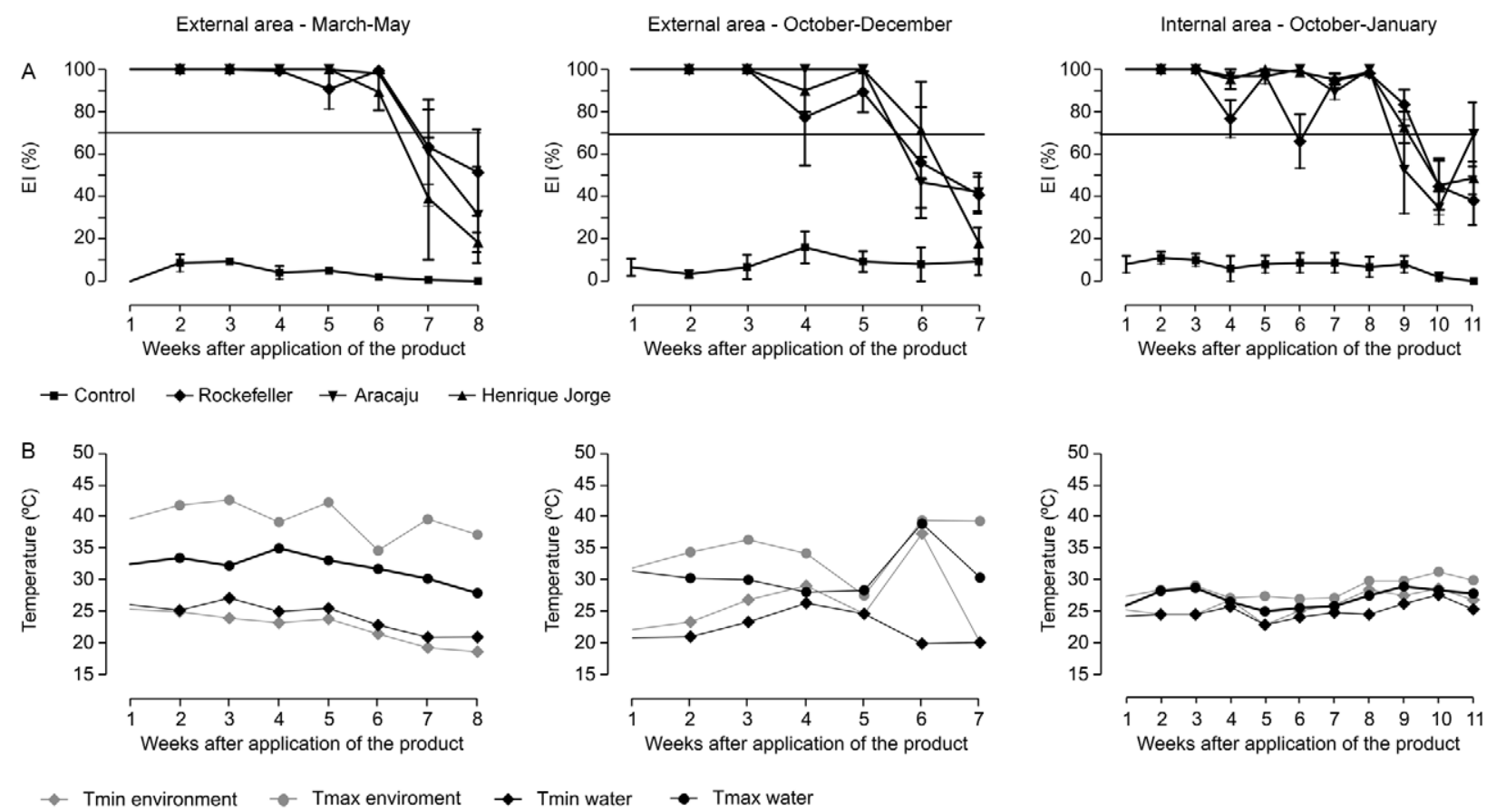

Fig. 5: novaluron persistence evaluation in field simulated conditions of two Brazilian Aedes aegypti populations. A: only the condition with water replacement is shown ( $20 \%$ of the container 3 times a week); B: values of environment and water temperatures during the corresponding assays (see Materials and Methods for details). The horizontal lines in A point to $70 \%$ adult emergence inhibition (EI), limit defined for the residual effect of the compound.

novaluron than Culex quinquefasciatus (Su et al. 2003), Aedes albopictus, Anopheles albimanus and Anopheles pseudopunctipennis (Arredondo-Jiménez \& Valdez-Delgado 2006), as judged by comparisons of the LCs for each species. Novaluron is also an effective inhibitor of Ae. aegypti adult emergence. In this work, we obtained an $\mathrm{EI}_{99}$ of $0.3 \mu \mathrm{g} / \mathrm{L}$, indicating a higher activity than triflumuron $\left(\mathrm{EI}_{99}\right.$ of $\left.1.8 \mu \mathrm{g} / \mathrm{L}\right)$ (Martins et al. 2008) and diflubenzuron $\left(\mathrm{EI}_{99}\right.$ of $\left.3.5 \mu \mathrm{g} / \mathrm{L}\right)$ (Fournet et al. 1993).

All of the populations evaluated in this work were susceptible to novaluron, regardless of their temephos or deltamethrin resistance status. Aracaju mosquitoes were even more susceptible to novaluron than the Rockefeller reference strain, although the $\mathrm{RR}_{90}$ of the Aracaju population to temephos was 12.9. Insect field populations that are resistant to chemical insecticides but more susceptible to IGRs than laboratory reference strains have already been reported, including $S$. littoralis resistant to chlorfluazuron (Ishaaya et al. 2003) and a Brazilian temephosresistant Ae. aegypti population that is more susceptible to methoprene than the Rockefeller strain (Braga et al. 2005). We found high novaluron slope values for all of the populations evaluated, a result that indicates homogeneity of the populations regarding this characteristic. The lowest slope, indicating higher heterogeneity, was found for the Henrique Jorge population, which exhibited the highest novaluron resistance ratio $\left(\mathrm{RR}_{00}\right.$ of 1.71).

There was no correlation among the tested populations between altered susceptibility to novaluron and resistance to temephos or deltamethrin, in contrast to the findings of Martins et al. (2008). These authors observed that in Ae. aegypti populations with a high temephos RR, triflumuron-induced mortality tended to occur later, towards the pupal stage.

Our results confirmed the efficacy of novaluron against $A$ e. aegypti under simulated field conditions. Persistence in the external area was lower than in indoor conditions, as previously observed by Montella et al. (2007) with temephos assays. High temperatures and exposure to light could explain the lower persistence of IGRs in external conditions, as these factors have been shown to be responsible for the rapid degradation of methoprene (Schaefer \& Dupras 1973, Mulla \& Darwazeh 1975).

Mulla et al. (2003) used $50 \mu \mathrm{g} / \mathrm{L}$ novaluron under simulated field conditions without water replacement and observed more than $70 \%$ mortality over 190 days in an external shaded area. The longer persistence of novaluron in those assays was partially attributed to the use of clay jars as the water containers.

We observed slight differences in persistence between the two external condition field tests. Surprisingly, lower persistence was obtained during the October-December assay, when fewer elevated temperatures were recorded. This result is most likely due to the wide variation in temperature observed during this period (Fig. 5).

We also noted a slightly lower novaluron susceptibility of the Rockefeller strain at various points during the field-simulated assays. This result could be due to differences in the larval physiological conditions: the Rockefeller strain is highly adapted to laboratory rearing 
and develops faster and more homogeneously than field populations. It has also been noted that sensitivity to novaluron decreases in the later larval instars (Mulla et al. 2003, Arredondo-Jiménez \& Valdez-Delgado 2006).

Unexpectedly, we did not observe differences in novaluron persistence EI between the conditions with or without water replacement. This result is in contrast with a report by Thavara et al. (2007), who obtained lower diflubenzuron persistence when the water was periodically replaced. Higher accumulation of organic matter in the condition without water replacement could account for the difference. Accordingly, Batra et al. (2005) observed a reduction in the effect of triflumuron in water containing high quantities of organic matter.

The two populations chosen for the simulated assays, Henrique Jorge and Aracaju, had the highest and the lowest novaluron RR, respectively. Although the $\mathrm{RR}_{90}$ values remained below 2.0 in both cases, suggestive of true susceptibility, the biological significance of these values is not known. The field-simulated assays showed equivalent novaluron residual effects for both populations, confirming the effectiveness of this CSI. This would be equivalent to say that there would be no commitment of field control of Ae. aegypti populations exhibiting a $\mathrm{RR}_{90}$ of up to 1.7 , the highest novaluron $\mathrm{RR}$ found in this work.

The recent WHO approval of the use of novaluron in drinking water opens up the possibility of using this CSI to control Ae. aegypti larvae. Our results indicate that novaluron is effective against field populations, even temephos and deltamethrin resistant ones, in both laboratory and simulated field conditions under Brazilian climate conditions. Together, our data show that novaluron could potentially be used to control immature dengue vectors. However, care should be taken to monitor possible resistance selection or dissemination to keep this product as a tool for effective dengue vector control.

\section{ACKNOWLEDGEMENTS}

To Gilberto Couto Alcântara and Diego de Lacerda Rosa, for technical assistance, and to Heloisa Maria Nogueira Diniz (Serviço de Produção e Tratamento de Imagem/IOC) and Gustavo Lazzaro Resende (UENF Campo Goytacazes), for help with the figures.

\section{REFERENCES}

Arredondo-Jiménez JI, Valdez-Delgado KM 2006. Effect of Novaluron (Rimon ${ }^{\circledR} 10 \mathrm{EC}$ ) on the mosquitoes Anopheles albimanus, Anopheles pseudopunctipennis, Aedes aegypti, Aedes albopictus and Culex quinquefasciatus from Chiapas, Mexico. Med Vet Entomol 20: 377-387.

Batra CP, Mittal PK, Adak T, Ansari MA 2005. Efficacy of IGR compound Starycide $480 \mathrm{SC}$ (Triflumuron) against mosquito larvae in clear and polluted water. $J$ Vect Born Dis 42: 109-116.

Braga IA, Gomes AC, Nelson M, Mello RCG, Bergamaschi DP, Souza JMP 2000. Comparação entre armadilha larvária e armadilha de oviposição para detecção de Aedes aegypti. Rev Soc Bras Med Trop 33: 347-353.

Braga IA, Lima JBP, Soares SS, Valle D 2004. Aedes aegypti resistance to temephos during 2001 in several municipalities in the states of Rio de Janeiro, Sergipe and Alagoas, Brazil. Mem Inst Oswaldo Cruz 99: 199-203.
Braga IA, Mello CB, Montella IR, Lima JBP, Martins-Jr AJ, Medeiros PFV, Valle D 2005. Effectiveness of methoprene, an insect growth regulator, against temephos-resistant Aedes aegypti populations from different Brazilian localities under laboratory conditions. J Med Entomol 42: 830-837.

Braga IA, Valle D 2007. Aedes aegypti: vigilância, monitoramento da resistência e alternativas de controle no Brasil. Epidemiol Serv Saude 16: 295-302.

Brogdon WG, McAllister JC 1998. Insecticide resistance and vector control. Emerg Infect Dis 4: 605-613.

Câmara FP, Theophilo RGG, Santos GT, Pereira SRG, Câmara DCP, Matos RRC 2007. Estudo retrospectivo (histórico) da dengue no Brasil: características regionais e dinâmicas. Rev Soc Bras Med Trop 40: 192-196.

Campos J, Andrade CFS 2003. Susceptibilidade larval de populações de Aedes aegypti e Culex quinquefasciatus a inseticidas químicos. Rev Saude Publica 3: 523-527.

Claro LBL, Tomassini HCB, Rosa MLG 2004. Prevenção e controle do dengue: uma revisão de estudos sobre conhecimentos, crenças e práticas da população. Cad Saude Publica 20: 1447-1457.

da-Cunha MP, Lima JBP, Brogdon WG, Moya GE, Valle D 2005. Monitoring of resistance to the pyrethroid cypermethrin in Brazilian Aedes aegypti (Diptera: Culicidae) populations collected between 2001 and 2003. Mem Inst Oswaldo Cruz 100: 441-444.

Davidson G, Zahar AR 1973. The pratical implications of resistance of malaria vectors to insecticides. Bull Wld Hlth Org 49: 475-483.

Durbin AP, Whitehead SS 2010. Dengue vaccine candidates in development. Curr Top Microbiol Immunol 338: 129-143.

Forattini OP 2002. Culicidologia Médica, Vol. II, Universidade de São Paulo, São Paulo, 860 pp.

Fournet F, Sannier C, Montney N 1993. Effects of the insect growth regulators OMS 217 and diflubenzuron on the reproductive potential of Aedes aegypti. J Am Mosq Control Assoc 9: 426-430.

Hartberg WK, Craig-Jr GB 1970. Reproductive isolation in Stegomyia mosquitoes. II Hybrid breakdown between Aedes aegypti and $A$. mascarensis. Evolution 24: 692-703.

Hoffmann KH, Lorenz MW 1998. Recent advances in hormones in insect pest control. Phytoparasitica 26: 1-8.

Ishaaya I, Kontsedalov S, Horowitz AR 2003. Novaluron (Rimon), a novel IGR: potency and cross resistance. Arch Insect Biochem Physiol 54: 157-164.

Ishaaya I, Mendensol Z, Melamed-Madjar V 1998. Effect of buprofezin on embryogenesis and progeny formation of the sweet potato whitefly Bemisia tabaci (Homoptera: Aleyrodidae). J Econ Entomol 81: 781-784.

Ishaaya I, Yablonski S, Mendelson Z, Mansour Y, Horowitz AR 1996. Novaluron (MCW-275), a novel benzoylphenyl urea, suppressing developing stages of lepidopteran, whitefly and leafminer pests. Proceedings of the 1996 Brighton Crop Protection Conference Pests and Disease, Brighton, United Kingdom, BCPC Publications, Croydon, p. 1013-1020.

Lima JBP, Da-Cunha MP, Silva-Jr RCS, Galardo AKR, Soares SS, Braga IA, Ramos RP, Valle D 2003. Resistance of Aedes aegypti to organophosphates in several municipalities in the state of Rio de Janeiro and Espírito Santo, Brazil. Am J Trop Med Hyg 68: 329-333.

Lima JBP, Melo NV, Valle D 2005. Residual effect of two Bacillus thuringiensis var israelensis products assayed against Aedes aegypti (Diptera: Culicidade) in laboratory and outdoors at Rio de Janeiro, Brazil. Rev Inst Med Trop Sao Paulo 47: 125-130. 
Macoris MLG, Andrighetti MTM, Otrera VCG, Carvalho LR, Caldas Júnior AL, Brogdon WG 2007. Association of insecticide use and alteration on Aedes aegypti susceptibility status. Mem Inst Oswaldo Cruz 102: 895-900.

Macoris MLG, Andrighetti MTM, Takaku L, Glasser CM, Garbeloto C, Cirino VBC 1999. Alteration in susceptibility response of Aedes aegypti to organophosphates in cities in the state of São. Paulo, Brazil. Rev Saude Publica 33: 521-522.

Martins AJ, Belinato TA, Lima JBP, Valle D 2008. Chitin synthesis inhibitor effect on Aedes aegypti populations susceptible and resistant to organophosphate temephos. Pest Manag Sci 64: 676-680.

Martins F, Silva IG 2004. Avaliação da atividade inibidora do diflubenzuron na ecdise das larvas de Aedes aegypti (Linnaeus, 1762) (Diptera, Culicidae). Rev Soc Bras Med Trop 37: 135-138.

Medronho RA 2006. Dengue e o ambiente urbano. Rev Bras Epidemiol 9: 159-161.

Merzendorf H 2005. Insect chitin synthases: a review. J Comp Physiol B 176: $1-15$

Merzendorfer H, Zimoch L 2003. Chitin metabolism in insects: structure, function and regulation of chitin synthases and chitinases. J Exp Biol 206: 4393-4412.

Montella IR, Martins AJ, Viana-Medeiros PF, Lima JBP, Braga IA, Valle D 2007. Insecticide resistance mechanisms of Brazilian Aedes aegypti populations from 2001 to 2004. Am J Trop Med Hyg 77: 467-477.

MS/SVS - Ministério da Saúde/Secretaria de Vigilância em Saúde 2006. Avaliação da eficácia de análogos de hormônio juvenil e inibidores de síntese de quitina no controle de Aedes aegypti. Available from: sms.pmmp.rj.gov.br.

MS/SVS - Ministério da Saúde/Secretaria de Vigilância em Saúde 2007. Dengue no Brasil. Balanço de dengue janeiro a julho de 2007. Available from: portal.saude.gov.br/portal/arquivos/pdf/ dengue_0210.pdf.

MS/SVS - Ministério da Saúde/Secretaria de Vigilância em Saúde 2009. Dengue no Brasil. Informativo Epidemiológico 17/2009. Período: semana epidemiológica 1 a 26 de 2009. Available from: portal. saude.gov.br/portal/arquivos/pdf/informe_ate_semana_26.pdf.

Mulla MS 1974. Laboratory and field evaluation of insect growth regulators against mosquitoes. Proc Papers Calif Mosq Contr Assoc 42: 175-176.

Mulla MS, Darwazeh HA 1975. Activity and longevity of insect growth regulators against mosquitoes. J Econ Entomol 68: 791-794.
Mulla MS, Thavara U, Tawatsin A, Chompoosri J, Zaim M, Su T 2003. Laboratory and field evaluation of novaluron a new acylurea insect growth regulator against Aedes aegypti (Diptera: Culicidae). $J$ Vector Ecol 28: 241-254.

Nogueira RME, Miagostovick MP, de Filippis AMB, Pereira MAS, Schatzmayr HG 2001. Dengue virus type 3 in Rio de Janeiro, Brazil. Mem Inst Oswaldo Cruz 96: 925-926.

Paixão KS 2007. Avaliação do controle químico de adultos de Aedes (Stegomyia) aegypti (Linnaeus, 1762) (Diptera: Culicidae) de Fortaleza por meio de métodos convencionais e das armadilhas $B G$-Sentine $l^{\circledR}$ e MosquiTRAP ${ }^{\circledR}$, MSc Dissertation, Universidade Federal de Minas Gerais, Belo Horizonte, 119 pp.

Raymond M 1985. Presentation d'une programme d'analyse logprobit pour microordinateur. Cahiers Orstrom Ser Ent Med Parasitol 22: $117-121$.

Schaefer CH, Dupras EF 1973. Persistence of ZR-515 in water. J Econ Entomol 66: 923-925.

Su T, Mulla MS, Zaim M 2003. Laboratory and field evaluations of novaluron, a new insect growth regulator (IGR) against Culex mosquitoes. J Am Mosq Control Assoc 19: 408-418.

Talaat AI, Mulla MS 1984. Morphogenetic and histopathological effects of the insect growth regulator cyromazine in larvae of Culex quinquefasciatus (Diptera: Culicidae). J Med Entomol 21: 427-431.

Teixeira MG, Barreto ML, Guerra Z 1999. Epidemiologia e medidas de prevenção do dengue. Inf Epidemiol SUS 8: 5-33.

Thavara U, Tawatsin A, Chansang C, Asavadachanukorn P, Zaim M, Mulla MS 2007. Simulated field evaluation of the efficacy of two formulations of diflubenzuron, a chitin synthesis inhibitor against larvae of Aedes aegypti (L) (Diptera: Culicidae) in water-storage containers. South Asian J Trop Med Public Health 38: 269-275.

WHO - World Health Organization 1981. Instructions for determining the susceptibility or resistance of mosquito larvae insecticides. WHO/VBC/81.807. Available from: whqlibdoc.who.int/ temp/WHO VBC 81.807.pdf.

WHO - World Health Organization 1998. Test procedures for insecticide resistance monitoring in malaria vectors, bio efficacy and persistence of insecticides on treated surfaces. WHO/CDS/CPC/ MAL/98.12. Available from: whqlibdoc.who.int/hq/1998/WHO CDS_CPC_MAL_98.12.pdf.

WHO - World Health Organization 2007. Novaluron in drinking-water: use for vector control in drinking-water sources and containers. WHO/SDE/WSH/07.01/11. Available from: bvsde.paho.org/cd-gdwq/Biblioteca/Support\%20docs\%20GDWQ/novaluron2ndadd.pdf. 




Floating apparatus added to the buckets to separate specimens included at different weeks. A: buckets with the floating apparatus during assay; B: detail of the floating device totally covered with a nylon mesh; C: removal of adult mosquitoes with an aspirator. 